\title{
Central nervous system involvement in optic neuritis
}

\author{
EACM SANDERS,${ }^{*}$ JPH REULEN, $\dagger$ LAH HOGENHUIS $\ddagger$
}

From the Department of Neurology, Academisch Ziekenhuis, Leiden, ${ }^{*}$ the Department of Medical Physics, Vrije Universiteit, Amsterdam, $\dagger$ the Department of Neurology, Ziekenhuis "De Goddelijke Voorzienigheid", Sittard, $\ddagger$ The Netherlands

SUMMARY Thirty patients with clinically uncomplicated optic neuritis were subjected to a battery of electrophysiological tests, including visual evoked response (VER), auditory brainstem evoked response (ABER) and somatosensory evoked response (SSER). Blink reflex, electronystagmography (ENG), and computed tomography examinations were also carried out on all patients. These non-invasive tests indicated that in 11 of the 30 patients $(37 \%)$, the optic neuritis was a symptom of subclinical multiple sclerosis, and that another five patients showed signs of mild central nervous system (CNS) involvement which may develop into multiple sclerosis later. This was confirmed by cerebrospinal fluid (CSF) analysis, using isoelectric focusing, showing oligoclonal extra bands in 11 out of these sixteen. A new classification of optic neuritis is proposed on the basis of these findings.

Optic neuritis is frequently observed in patients with multiple sclerosis. This was reported by Parinaud ${ }^{1}$ and Gnauck $^{2}$ as early as 1884 and confirmed by Uhthoff (1889). ${ }^{3}$ Necropsy of multiple sclerosis patients often revealed demyelinating lesions in the optic nerves. ${ }^{45}$ Optic neuritis frequently becomes chronic in multiple sclerosis patients, with only partial or no recovery, and may ultimately result in a central scotoma with serious loss of central visual acuity. Complete recovery is rare. A clinically observed attack of optic neuritis may be seen in approximately $50 \%$ of multiple sclerosis patients during the course of the disease. ${ }^{6}$ Conversely, a high percentage of patients who suffered visual loss due to acute optic neuritis, develop signs or symptoms of manifest multiple sclerosis later on. Leibowitz et al retrospectively found optic neuritis to be the first observed symptom of multiple sclerosis in nearly $15 \%$ of their cases. A recent literature-review confirmed this. ${ }^{8}$

Pure optic neuritis gives a characteristic clinical picture with a fairly favourable short-term prognosis. The long-term prognosis is less certain, however, and it is still not clear which of the optic neuritis patients will ultimately develop multiple

Address for reprint requests: EACM Sanders, MD, PhD, Academisch Ziekenhuis Leiden, Rijnsburgerweg 10, 2333 AA Leiden, The Netherlands.

Received 25 May 1983 and in revised form 9 September 1983. Accepted 24 September 1983. sclerosis, and which specific clinical or laboratory parameter can serve as an indicator of that risk. Sandberg-Wollheim ${ }^{9}$ found cerebrospinal fluid (CSF) analysis in optic neuritis patients was not a reliable predictive factor for the risk of future multiple sclerosis. Nikoskelainen et $\mathrm{al}^{10}$ suggested that an increased IgG level or a decreased serum/CSF measles antibody ratio might imply a higher risk of developing multiple sclerosis. A normal CSF does not, however, rule out disseminated demyelination.

Recently developed non-invasive electrophysiological investigative techniques improve the certainty of demonstrating optic nerve lesions in optic neuritis and multiple sclerosis patients. Richy et $a l^{11}$ who first recorded visual evoked response (VER) in 50 multiple sclerosis patients, found an increased latency in 20 patients. Halliday $\mathrm{et} \mathrm{al}^{12}$ used pattern-reversal checkerboard VER in 19 patients with acute unilateral optic neuritis and found an abnormally delayed latency in 17 patients (mean $\mathrm{P} 100=155 \mathrm{~ms}$ ). These P100 latency abnormalities were still observed after visual acuity had returned to normal. VER abnormalities were not found in the unaffected eyes.

The most characteristic VER abnormalities in optic neuritis patients are an increased peak latency of the major component (P100) and a reduced amplitude. This amplitude reduction is mostly seen in patients with acute optic neuritis. ${ }^{12}$ Although VER observations are very useful for the diagnosis of (acute) optic neuritis, they have no predictive value 
as regards the ultimate development of multiple sclerosis.

The definite clinical diagnosis of multiple sclerosis requires the finding of at least two anatomically separate lesions in the CNS white matter. ${ }^{13}$ Evoked responses, electromyography (blink reflex) and electronystagmography (ENG) may reveal the presence of clinically non-symptomatic (silent) plaques, and have been widely used during the past decade to detect the mandatory second lesions. ${ }^{14-20}$

CT scanning, as a non-invasive tool for the detection of hypodense or contrast-enhanced hyperdense lesions in the acute phases of multiple sclerosis, has been subject of several studies. ${ }^{21-25}$ Only Cala et $\mathbf{l}^{23}$ found hypodense areas in the optic nerve in $53 \%$ of multiple sclerosis patients.

The main aim of the present investigation was to find out whether clinically uncomplicated optic neuritis, as a possible indicator of future multiple sclerosis, is likely to be associated with clinically latent CNS dysfunction. For this purpose VER, ABER, SSER, blink reflex, ENG and CT scan studies were carried out on a group of 30 patients. The relation between the results of these studies and those of isoelectric focusing of the CSF, was assessed by statistical analysis.

\section{Methods}

\section{Patients}

Thirty patients ( 21 females; 9 males; mean age 32 years) with appreciable visual loss, who had undergone ophthalmological screening by funduscopy, electrooculography and electroretinography, were referred to the neurology department with suspected optic neuritis, after other causes of visual loss had been excluded. All patients initially suffered visual loss in one eye; only one had a subsequent relapse in the other eye. Nineteen were found to have recovered completely on physical re-examination within 6 months of the attack, whereas 11 kept complaining of a persistent scotoma, which was checked by campimetry. The patient with a relapse in the contralateral eye did not recover after the second attack. His visual acuity remained $15 / 60$ in the right eye and 10/60 in the left one.

Unless otherwise mentioned, the measurements described below were carried out shortly after referral to the neurology department.

\section{Visual Evoked Response (VER)}

VER recordings were obtained by a pattern-reversal method, ${ }^{12}$ with a black-and-white checkerboard pattern projection on a TV screen, subtending a visual angle of $33^{\circ} 2^{\prime}$ The luminance contrast of the pattern was $1: 14$. Silver-silver chloride scalp electrodes were placed at the points $\mathrm{O}_{1}$ (left occipital) and $\mathrm{O}_{2}$ (right occipital) with a reference electrode at $C_{2}$. The patients were seated $1 \mathrm{~m}$ in front of the TV screen. VER signals were measured by stimulation of both eyes simultaneously, and for each eye separately with the other eye covered.
Responses were recorded after passage through a bandpass filter $(1-100 \mathrm{~Hz})$; the results were expressed as the average of 248 individual responses. The average VER signals were plotted for visual inspection. The mean latency time of the P100 peak, as measured in 15 normal controls, was $105 \mathrm{~ms}$ (SD $6.5 \mathrm{~ms}$ ). The VER was judged to be abnormal when the latency time was $105 \mathrm{~ms}$ plus $3 \times$ the SD (124.5 ms), or when a difference of more than $3 \times$ the SD was noted between the left and right eye.

All previous VER studies ${ }^{12} 2728$ but one ${ }^{26}$ in multiple sclerosis or optic neuritis show the pattern-reversal checkerboard technique to be more sensitive than the flash technique for the detection of optic nerve lesions.

\section{Auditory brainstem evoked response. (ABER)}

ABER recordings were obtained using an averaging method. ${ }^{19}$ Silver-silver chloride scalp electrodes were placed on both mastoids $\left(A_{1}, A_{2}\right)$ and over the vertex (reference $\mathrm{C}_{2}$ ). Successive "clicks" (frequency $15 \mathrm{~Hz}$ ) were presented via a headphone (pulse duration $0.1 \mathrm{~ms}$ ). The stimulus intensity was $70 \mathrm{~dB}$ above the normal hearing level.

Stimuli were applied unilaterally, while responses were recorded bilaterally, after passage through a bandpass filter $(80-3500 \mathrm{~Hz})$. Each ABER reading consisted of the average of 2048 responses. The parameters studied were the latency times of the IIIrd, IVth and Vth peaks and the interval between the IIIrd and Vth peaks. Amplitude abnormalities were not covered in this study. Normal mean values, obtained from a group of 15 control subjects, were 3.85 (SD 0.23) ms for the IIIrd, 5.07 (SD 0.2) ms for the IVth and 5.70 (SD 2.0) ms for the Vth peak. The interval between the IIIrd and Vth peaks was 1.98 (SD 0.18) ms. The ABER was considered as abnormal when the latency time of each peak, or the interval between the IIIrd and $V$ th peak exceeded the mean plus $3 \times$ the SD. A difference between the left and right IIIrd-Vth peak interval of more than $3 \times \mathrm{SD}$ was also considered as abnormal.

\section{Somatosensory evoked response (SSER)}

The SSER was studied by unilateral stimulation of the median nerve at the wrist, using repetitive current pulses of $0.1 \mathrm{~ms}$ duration and a frequency of $10 \mathrm{~Hz}$. The stimulus intensity was chosen far enough above the motor threshold level of the thenar muscle, to give an adequate response. The signals picked up by scalp electrodes placed at the vertex (reference; Fz) C3, C4 and C7 were passed through a bandpass filter $(80-3500 \mathrm{~Hz})$, and averaged (512 sweeps) before being recorded.

The interpretation of the SSER results was based on the time interval between the N14 and N20 peaks. The normal range of values of this delay was established in 15 healthy control subjects (mean $5.50 \mathrm{~ms}$; SD 0.7). A time interval exceeding the mean plus $3 \mathrm{SD}$, or a difference between the mean values for the two wrists exceeding $3 \mathrm{SD}$ was judged to be abnormal.

Because of the poor reproducibility of SSER amplitudes, amplitude information was not analysed further.

\section{Blink reflex}

The latency of the blink reflex was measured by the method described by Ongerboer de Visser and Goor ${ }^{30}$ and 
Kimura, ${ }^{31}$ involving stimulation of the supra-orbital nerves with a $400 \mathrm{~mA}$ pulse of $0.1 \mathrm{~ms}$ duration. The blink reflex for each eyelid was recorded using coaxial needle electrodes in the inferior orbicularis muscle. The signals were passed through a bandpass filter $(200 \mathrm{~Hz}-10 \mathrm{kHz})$ and measured over $100 \mathrm{~ms}$, starting from the presentation of the stimulus. The latency time was measured from the start of the oscilloscope sweep to the initial deflection of the evoked muscle potential.

Normal latency values, obtained from 15 healthy controls, were between 10 and $12 \mathrm{~ms}$ for the $\mathrm{R} 1$ response and between 21 and $40 \mathrm{~ms}$ for the bilateral $\mathrm{R} 2$ response. A difference between the left-right $R 1$ response of more than $1.5 \mathrm{~ms}$ and of more than $9 \mathrm{~ms}$ for the left-right R2 response was judged to be abnormal.

This method is slightly more invasive than the others described in this paper, but was well tolerated by all subjects.

\section{Electronystagmography. (ENG)}

In this method (see ref 19)) eye-movements were followed with silver-silver chloride electrodes taped on the inner and outer canthi of both eyes.

The visual stimuli for investigating horizontal saccadic eye movements were provided by red light-emitting diodes $(\lambda=635 \mathrm{~nm})$, mounted on a horizontal cylindrical screen (radius $1 \mathrm{~m}$ ), with the patient's eyes situated at the centre of curvature. Initially the patient was asked to look at the centre of the screen, and the first stimulus appeared there. About 50 stimuli in all were presented, in a randomsequence, at positions subtending angles of 10,20 or 30 degrees to the left or the right of the initial position. The parameters studied were: (1) the saccadic latency, (2) the saccadic velocity and (3) the saccadic accuracy.

Horizontal smooth-pursuit eye-movements were elicited by a target moving in simple harmonic motion (amplitude: $12^{\circ}$ ) along a horizontal line through the fovea, produced by a laserbeam $(\lambda=630 \mathrm{~nm}$; power $0.1 \mathrm{~mW})$. Stimulus frequencies were between 0.2 and $1.0 \mathrm{~Hz}$ ).

The eye-movement signals were displayed on an oscilloscope screen and simultaneously recorded on magnetic tape (Bell and Howell CR 3000). A complete eyemovement test lasted about 30 minutes and did not cause the patients any discomfort.

\section{CT scans}

CT scans were performed with a third-generation $256 \times 256$ matrix scanner. The collimator was $8 \mathrm{~mm}$. Both normal and contrast-enhanced scans were obtained in each patient.

A special scan was made through the orbits for the investigation of the optic nerves in the acute stages of the optic neuritis attack, if the patients were available for observation at this time.

Cerebrospinal fuid (CSF) analysis

The method described by Mancini ${ }^{32}$ was used to test the quantitative intrathecal IgG synthesis in the CSF of our patients. Immunoglobuline $\mathrm{G}$ was qualified by isoelectric focusing. ${ }^{33}$

\section{Results}

The VER study revealed increased P100 latencies in the affected eyes of all optic neuritis patients. The mean latency of the P100 peak was 140 ms (SD $8.0 \mathrm{~ms}$ ). Seven patients showed an abnormal delay of the P100 peak in the contralateral eye (mean $135 \mathrm{~ms}$; SD 7.0). There was no significant correlation between the severity of the visual loss, as found by physical examination, and the increase in VER latency. Only one of the seven patients with contralateral VER abnormalities complained of visual loss on that particular side. Amplitude aspects were not covered in this study.

Ten patients (33\%) showed an abnormal delay between the IIIrd and Vth peak in the ABER recording. In seven of these patients, ABER abnormalities were found in both left and right side. The other three patients showed an unilateral ABER disorder.

Abnormally high time-intervals between the SSER N14 and N20 peaks were found in six patients (20\%). Two patients showed a bilateral increase in the N14-N20 interval.

An abnormal blink reflex was recorded in five patients $(17 \%)$. These disorders were always unilateral and were considered in all cases to be due to abnormal delay in $\mathrm{R} 1$ response.

Abnormal eye movements were recorded in nine patients $(30 \%)$, of whom five showed increased saccadic latency, one showed asymmetrical smoothpursuit eye movements only, and three a combination of both saccadic and smooth-pursuit eyemovement disorders. In one patient, the recorded saccadic eye movements were so abnormal as to suggest internuclear ophthalmoplegia. One patient (a 16-year-old girl) gave saccadic latencies of $500 \mathrm{~ms}$ and $450 \mathrm{~ms}$ for the left and right eye respectively. In this girl, who had optic neuritis of the right eye, the VER latency was $155 \mathrm{~ms}$ for the right and $120 \mathrm{~ms}$ for the left eye. Accordingly the increase in saccadic latencies are likely to be caused by lesions other than only the optic nerve involvement ${ }^{19}$ (normal saccardic latency $250 \mathrm{~ms}$ ).

In summary, apart from the VER disorders on the affected side (which were found in all patients), $23 \%$ of the patients showed a VER abnormality of the non-affected eye and $50 \%$ of the patients showed one or more electrophysiological abnormalitie(s) in CNS functional systems other than the optic nerves. The results for all electrophysiological tests are summarised in fig 1.

Two patients showed hypertrophy of the affected optic nerve in the special scan through the orbits (one example is given in fig $2 a$ ) and hyperdense contrast-enhanced areas at other levels (fig 2b). 


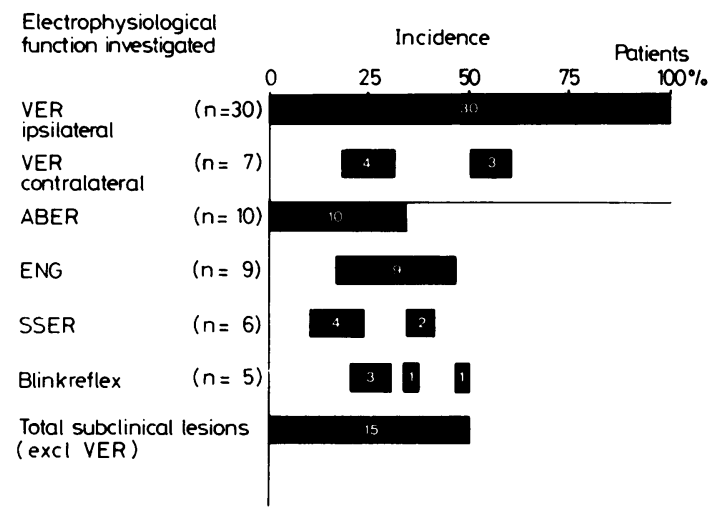

Fig 1 Distribution of the subclinical electrophysiological disorders detected in the 30 optic neuritis patients. This figure shows the overlap between the ABER, SSER, blink reflex and over all eye-movement disorders detected in the 30 optic neuritis patients. Each disorder detected in an individual patient is represented by a small black rectangle; all the rectangles in a given row represent the incidence of a particular disorder in the group of 30 optic neuritis patients, while all the rectangles vertically above one another represent the various disorders detected in a given patient. The VER in the eye with clinical symptoms of optic neuritis was disturbed in all cases. The VER abnormalities in the contralateral eye are also given (row 2), but are not included in the total of subclinical lesions (bottom row).

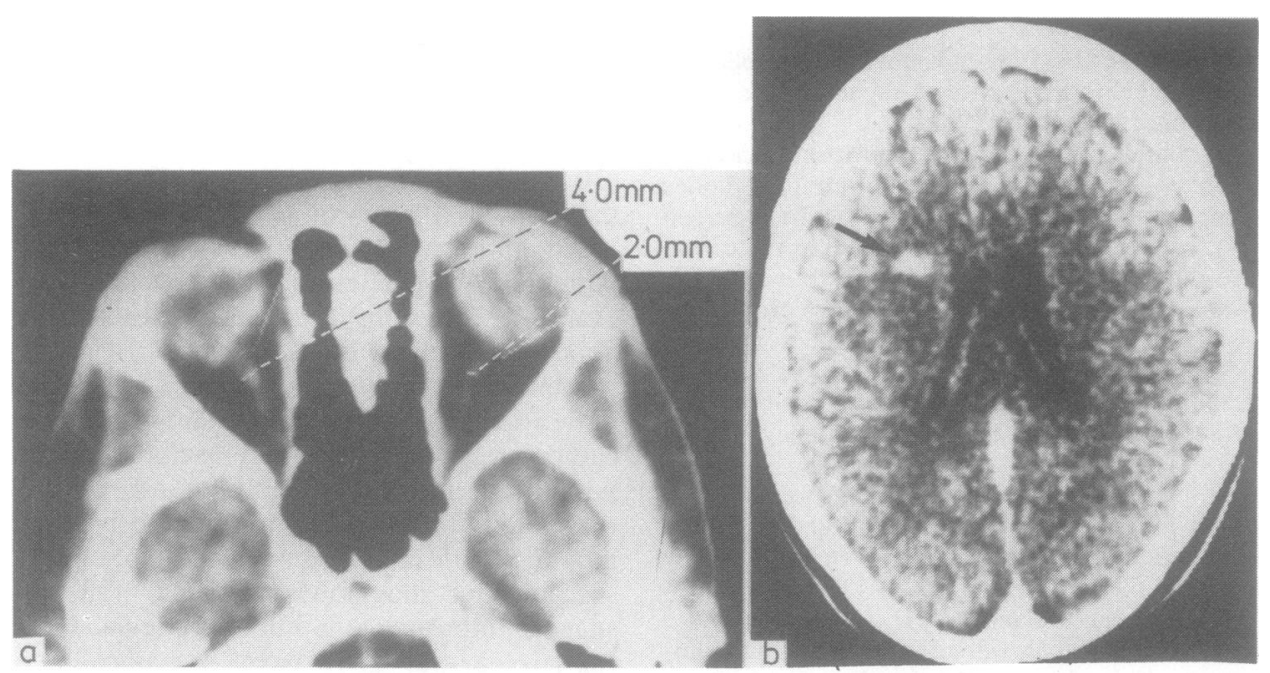

Fig 2 CT scans of a 34-year-old female patient with acute optic neuritis (a) increased diameter of the left optic nerve is clearly visible; (b) this scan taken at a higher level, shows a contrast-enhanced hyperdense area (see arrow), which is judged to be due to a demyelinating plaque. (The CT scan through the optic nerve is not perfectly horizontal, but on other levels through the optic nerves, the left lasted consequently larger than the right).

The patient who suffered a relapse of optic neuritis was subjected to CT scanning on four separate occasions, over a period of nine months (see fig 3), all scans being made at the same sagittal level. It is striking that each scan shows a contrastenhanced lesion at a different location.

Including the above-mentioned three patients, a total of six patients $(20 \%)$ showed hyperdense hemispheral lesions. The other 24 patients all had a normal CT scan.

In 14 patients $(47 \%)$, isoelectric focusing showed oligoclonal IgG bands in the CSF. The number of bands lies between 3 to 15 (mean 7). Only three of these 14 patients showed an IgG index higher than 0.85 .

The overall electrophysiological, CT scan and CSF findings are summarised in fig 4 .

\section{Discussion}

There is no way of predicting with certainty whether an individual patient with optic neuritis, is going to develop multiple sclerosis. In a literature review, the proportion of optic neuritis patients, later developing multiple sclerosis-related signs, varied from $8 \%$ to $80 \% .^{8}$ This difference is probably due to factors, 


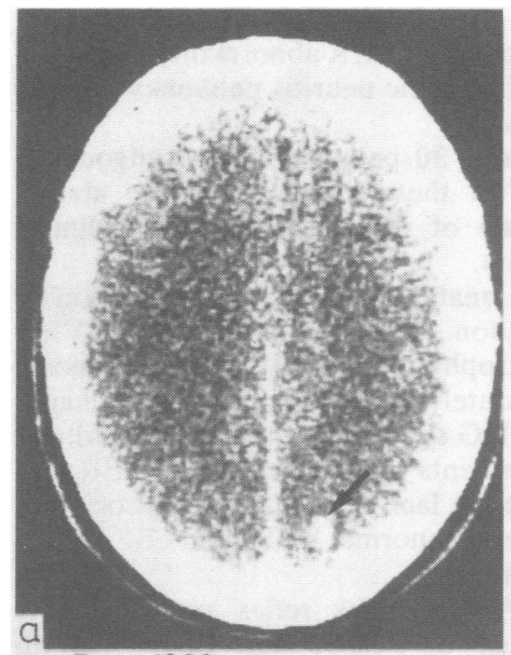

Dec 1980

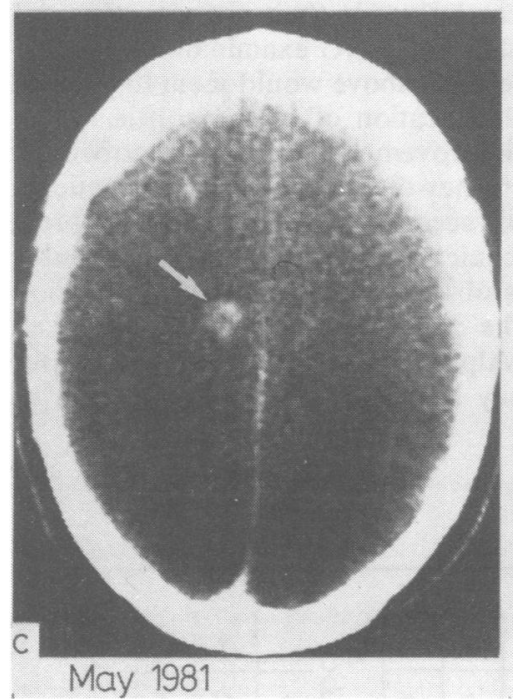

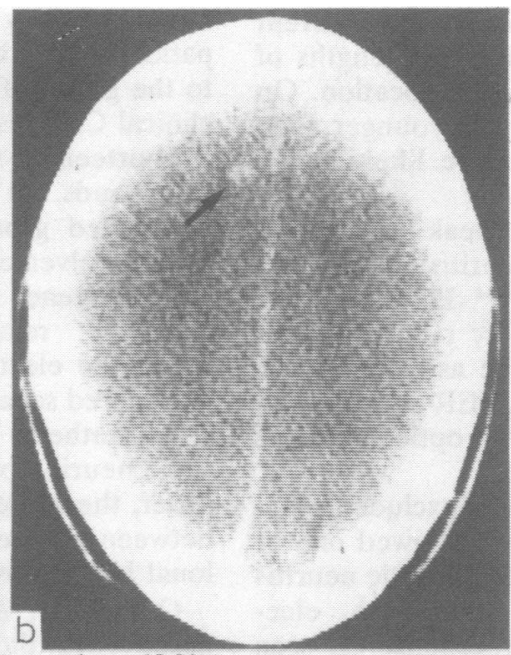

Apr 1981

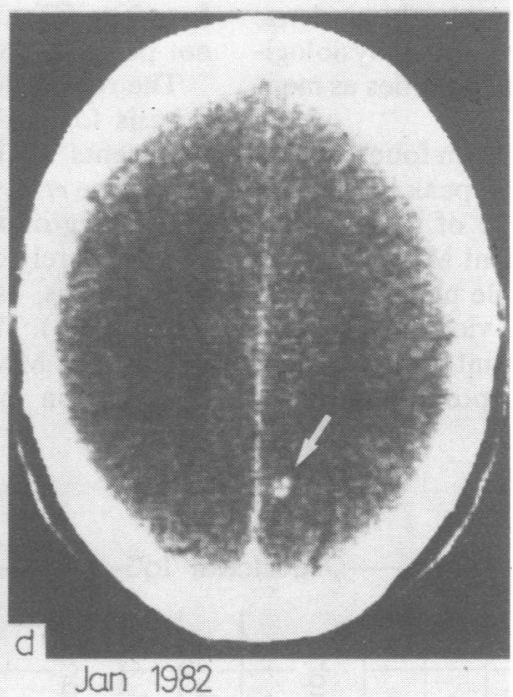

Fig 3 The CT scans of a 25-year-old male patient, with a contralateral relapse of optic neuritis, all taken at the same level on different dates after the initial attack of optic neuritis in December 1980, (a) December 1980, (b) April 1981, (c) May 1981 and (d) January 1982) on the site of which (see arrows) appears to vary with time. This patient had no clinical signs or symptoms related to multiple sclerosis throughout this study.

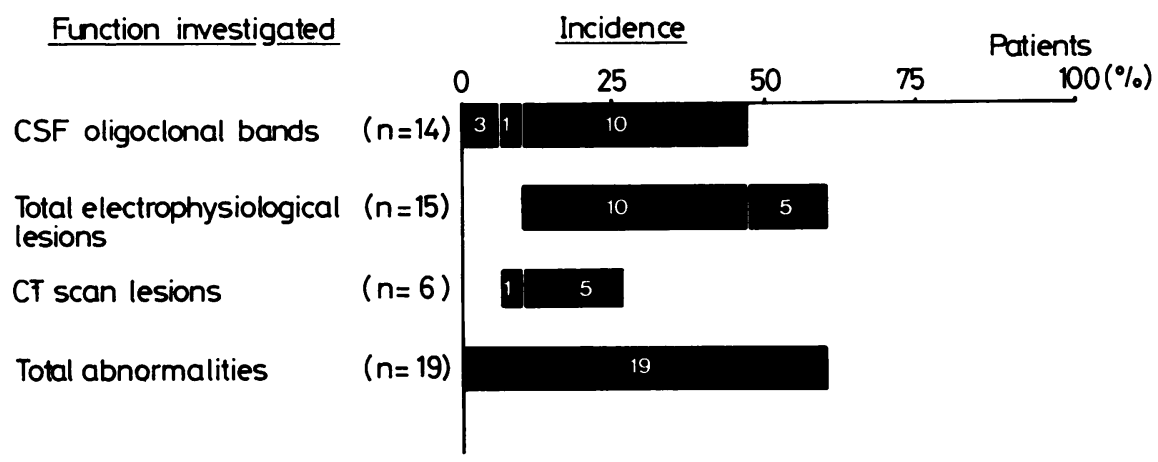

Fig 4 Distribution of the subclinical CNS abnormalities detected in the 30 optic neuritis patients. Nineteen patients (63\%) gave abnormal results in one or more of the tests represented in this figure. For further details, see caption to fig. 1. 
such as the different diagnostic criteria, the different methods of statistical analysis, different lengths of follow-up period, and the geographic location. On average, optic neuritis patients are younger than multiple sclerosis patients and more likely to be female. ${ }^{34}$

An abnormal increase in P100 peak latency was found in at least $90 \%$ of optic neuritis and definite multiple sclerosis patients. ${ }^{12} 272835$ However, this sign is not specific either for optic neuritis or for multiple sclerosis, nor needs to be associated with complaints of visual loss. Hence, VER examination does not help to determine whether optic neuritis is likely to lead to multiple sclerosis.

When all VER abnormalities were excluded, electrophysiological tests and CT scans showed one or more possible lesions in 16 of our 30 optic neuritis patients. Among these, five had both electrophysiological disorders and hyperdense CT scan lesions, six had a single electrophysiological abnormality and only one patient showed a hyperdense area on the CT scan, without any electrophysiological disorder (apart from VER abnormalities as mentioned.)

No definite explanation has yet been found for the occurrence of a delayed VER P100 peak in the contralateral, clinically unaffected eye of some of our patients. It could be due to a "silent MS plaque" in the clinically normal eye or a single plaque, located just within the optic chiasm. In view of the later possibility, we did not count contralateral VER delays as extra lesions for the purpose of statistical analysis. It may be mentioned, that four of the seven patients with a bilateral VER abnormality, belonged to the group of 16 optic neuritis patients with subclinical CNS lesions.

Fourteen of our 30 patients showed oligoclonal IgG bands, 11 of these belonging to the abovementioned group of 16 patients with subclinical CNS involvement.

Contingency analysis (fig 5) reveals a highly significant relation between contralateral VER delay, the electrophysiological or CT scan lesions, considered separately or together, on the one hand, and intrathecal IgG synthesis on the other hand. All optic neuritis patients had an ipsilateral VER disorder, therefore the lack of a significant association between ipsilateral abnormal VERs and CSF oligoclonal IgG is obvious.

Our VER, ABER, blink reflex and CSF data agree with those of Feasby and Ebers ${ }^{\mathbf{3 6}}$ in 36 uncomplicated optic neuritis patients. These authors found no CT scan lesions in their patients; they did not perform SSER and ENG examinations.

The results detailed above would seem to provide a basis for a classification of optic neuritis, which represents an improvement on that described by McAlpine et al. ${ }^{6}$ They divided optic neuritis patients into four groups, according to the absence or presence of purely clinical signs and symptoms of multiple sclerosis, as observed over a fairly long period (see table 1). The 30 patients in our study would all belong to McAlpine's first group. In fact, our classification may be regarded as a subdivision of

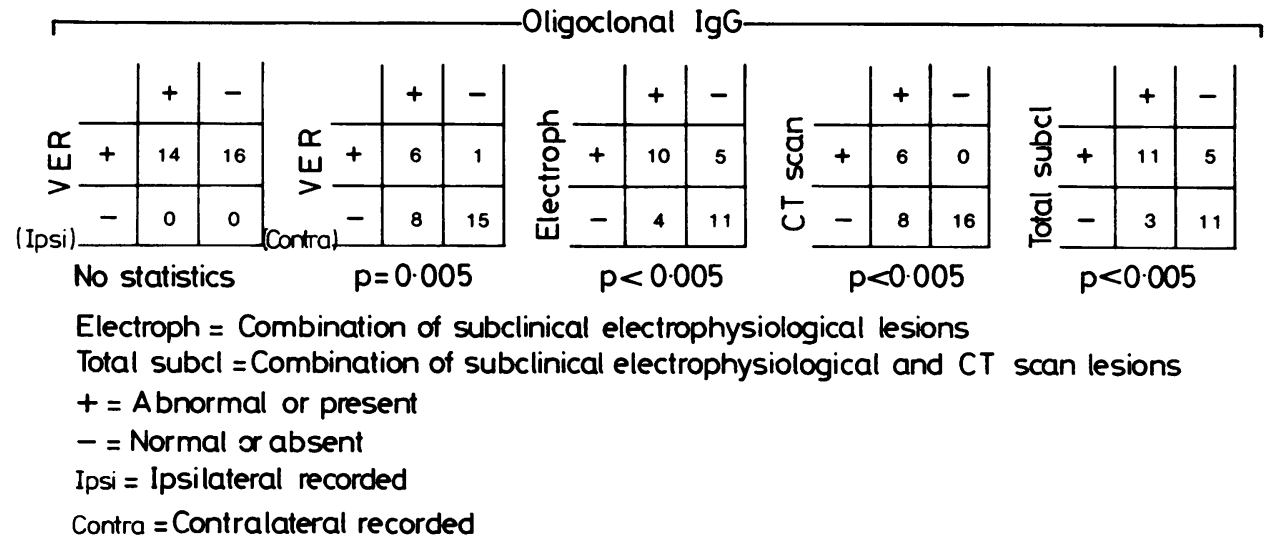

Fig 5 Contingency tables showing the statistical relations between the subclinical lesions and the finding of oligoclonal IgG in the CSF. Ipsilateral VER delay is the only disorder which shows no significant correlation with oligoclonal $\mathrm{IgG}$; all the other types of subclinical lesions detected, taken both individually and together, are significantly correlated with oligoclonal IgG. 
Table 1 Classification of optic neuritis according to McAlpine (1965).

Based on manifest clinical signs and symptoms of multiple sclerosis appearing after the initial attack.

Group 1: No concomitant clinical evidence of multiple sclerosis can be found during the patient's lifetime.

Group 2: Acute bilateral retrobulbar neuritis is preceded or followed by signs of an acute myelitis (Devic's neuromyelitis optica).

Group 3: Neurological signs, of the type within multiple sclerosis accompany or shortly follow on one or more attacks of optic neuritis, but subsequently there are no relapses and signs may disappear.

Group 4: Signs of multiple sclerosis accompany or follow one or more attacks of optic neuritis.

Table 2(a) Proposed new classification of optic neuritis. Based on early signs of subclinical CNS involvement at the time of the initial attack, derived from the results of electrophysiological tests, CT-scans and CSF analysis, which may indicate a risk of later development of multiple sclerosis.

Group 1: Optic neuritis without clinical signs or symptoms of multiple sclerosis and without signs of CNS involvement as determined by ABER, SSER, blink reflex or ENG tests. CT scans or CSF analysis (most of the patients in this group are likely to show VER delays, but this has been tound not to be predictive of future multiple sclerosis involvement).

Group II: Optic neuritis with VER delay in combination with signs of intrathecal IgG synthesis. This may be regarded as a demonstration of a monosymptomatic form of demyelination.

Group III: Optic neuritis with VER abnormalities and electrophysiological signs of CNS involvement, without intrathecal CSF synthesis. Multiple CNS involvement can be suspected in this group.

Group IV: Optic neuritis with hypo-or hyperdense areas in the CT scan, VER delays or/and other electrophysiological signs of CNS involvement in combination with intrathecal IgG synthesis in the CSF as detected by isoelectricfocusing. These patients can be regarded as already having "subclinical" multiple sclerosis.

(b) Classification of the 30 optic neuritis patients of the present study according to the newly proposed scheme.

\begin{tabular}{lll}
\hline Group & No of patients & $\%$ \\
\hline I & 11 & 37 \\
II & 3 & 10 \\
III & 5 & 16 \\
IV & 11 & 37 \\
\hline
\end{tabular}

McAlpine's group 1, making use of refined experimental techniques to increase predictability concerning the risk of subsequent development of multiple sclerosis at such an early stage as to allow suitable palliative measures to be taken.
In the new classification proposed, information on subclinical CNS involvement, in addition to that affecting the optic nerve at the time of the acute optic neuritis, is also taken into consideration (see table $2 a$ and $b$ ).

Thirty-seven per cent of the 30 patients examined $(n=11)$ belonged to our group I, that is they had optic neuritis without clinical signs and symptoms of multiple sclerosis, and without any of the signs of subclinical CNS involvement found in the other groups. Group II comprises those patients who had an optic neuritis with VER delay and intrathecal IgG, as detected by the isoelectric focusing technique $(n=3)$. Group III is constituted of optic neuritis patients with VER abnormalities and electrophysiological signs of general CNS involvement were observed, but without intrathecal IgG synthesis $(n=5)$. Members of this group may be suspected to have multiple CNS lesions, but firm evidence is lacking. Group IV (the other large group in our study; $n=11$ ) comprises VER delay, hyperdense areas in the CT scan and/or other electrophysiological signs of CNS involvement, in combination with intrathecal IgG synthesis, as detected by isoelectric focusing. These patients can be regarded as "subclinical" with regard to multiple sclerosis.

In agreement with previous reports, ${ }^{10} 3738 \mathrm{CSF}$ analysis is an important factor in this new classification.

The investigations in this study were mostly carried out in the acute phase of optic neuritis. It therefore can not be excluded that the patients of group III and IV have disseminated lesions at the onset of what may prove ultimately to be a monophasic illness (an episode of disseminated encephalo-myelitis with only one clinically evident lesion). Only a prospective study will reveal whether the 16 patients assigned to group III and IV, really are more at risk for developing multiple sclerosis than the patients in the other groups. Such prospective study may not only help to refine the frame of reference for classification of optic neuritis but may also provide a more detailed paradigm for future study of the association between optic neuritis and multiple sclerosis and a possible early diagnosis of the latter.

The present investigation does not give an unequivocal indication of which patients will develop multiple sclerosis and which will not. It does, however, single out the optic neuritis patient with a second lesion fairly accurately.

The authors are indebted to Prof Dr GW Bruyn (Leiden), Dr GHM van Lith (Rotterdam) and Dr RH Bathgate (Eindhoven) for critically reviewing this paper. Mrs I Harlaar-Kiela and Mrs MCL Vernet-Meijer prepared the manuscript. 


\section{References}

${ }^{1}$ Parinaud H. Troubles oculaires de la sclérose en plaques. Prog Méd (Paris), 1884;12:641.

${ }^{2}$ Gnauck R. Ueber Augenstörungen bei Multipeler Sklerose. Neurol Zbl 1884;3:313.

${ }^{3}$ Uhthoff $\mathbf{W}$. Untersuchungen über die bei der Multipeler Herdsklerose vorkommende Augenstörungen. Arch Psychiat Nervenkr 1889;21(55):303.

${ }^{4}$ Lumsden CE. The neuropathology of multiple sclerosis. In: Handbook of Clinical Neurology, 9. Vinken, PJ, Bruyn GW eds, Amsterdam, North-Holland Publ Co, 1970, p. 217-309.

${ }^{5}$ Ikuta F, Zimmerman HM. Distribution of plaques in seventy autopsy cases of multiple sclerosis in the United States. Neurology (Minneap) 1976; part II:26-28.

${ }^{6}$ McAlpine D, Lumsden CE, Acheson ED. Multiple Sclerosis. A reappraisal. Edinburgh, Livingstone Ltd, 1965.

${ }^{7}$ Leibowitz U, Alter M, Halpern L. Clinical studies of multiple sclerosis in Israel. IV. Optic neuropathy and multiple sclerosis. Arch Neurol 1966;14:459.

${ }^{8}$ Cohen MM, Lessell S, Wole PA. A prospective study of the risk of developing multiple sclerosis in uncomplicated optic neuritis. Neurology (Minneap) 1979;29:208-13.

9 Sandberg-Wollheim M. Optic neuritis: studies on the cerebrospinal fluid in relation to clinical course in 61 patients. Acta Neurol Scand 1975;52:167-8.

${ }^{10}$ Nikoskelainen E, Frey H, Salmi A. Prognosis of optic neuritis with special reference to cerebrospinal fluid immunoglobulins and measles virus antibodies. Ann Neurol 1981;9:545-50.

${ }^{11}$ Richey ET, Kooi KA, Tourtelotte WW. Visually evoked responses in multiple sclerosis. J Neurol Neurosurg Psychiat 1971;34:275-80.

${ }^{12}$ Halliday AM, McDonald WI, Mushin J. Delayed visual evoked response in optic neuritis. Lancet 1972;932985.

${ }^{13}$ Schumacher GA, Beebe G, Kibler RF et al. Problems of experimental trials of therapy in multiple sclerosis: report by the panel on the evaluation of experimental trials of therapy in multiple sclerosis. Ann New York Acad Sci 1965;122:522-86.

${ }^{14}$ Robinson K, Rudge P. Auditory evoked responses in multiple sclerosis. Lancet 1975;24:1164-6.

15 Robinson K, Rudge P. Abnormalities of the auditory evoked potentials in patients with multiple sclerosis. Brain 1977;100:19-40.

${ }^{16}$ Small DG, Matthews WB, Small M. The cervical somatosensory evoked potential (SEP) in the diagnosis of multiple sclerosis. $J$ Neurol Sci 1978;35:211-24.

${ }^{17}$ Yates SK, Brown WF. Light-stimulus-evoked blink reflex: methods, normal values, relation to other blink reflexes and observations in multiple sclerosis. Neurology (Minneap) 1981;31:272-81.

${ }^{18}$ Scarpaloz S, Tsalanikas C, Stanboulis E. Apport de l'epreuve vestibulaire rotatoire pendulaire au diagnostic de la form spinale de la sclérose en plaques. Rev Neurol (Paris) 1981;137 (2):147-51.
${ }^{19}$ Reulen JPH, Sanders EACM, Hogenhuis LAH. Eye movement disorders in multiple sclerosis and optic neuritis. Brain 1983;106:121-40.

${ }^{20} \mathrm{Kjear} \mathrm{M}$. Evoked potentials with special reference to the diagnostic value in multiple sclerosis. Acta Neurol Scand 1983;67:67-89.

${ }^{21}$ Gyldensted C. Computer tomography of the brain in multiple sclerosis. A radiological study of 110 patients with special reference to demonstration of cerebral plaques. Acta Neurol Scand 1976;53:386-89.

${ }^{22}$ Aita JF, Bennett DR, Anderson RE, Zitter F. Cranial CT appearances of acute multiple sclerosis. Neurology (Minneap) 1978;28(3):251-55.

${ }^{23}$ Cala LA, Mastaglia FL, Black JL. Computerized tomography of brain and optic nerve in multiple sclerosis. Observations in 100 patients, including serial studies in 16. J Neurol Sci 1978;36(3):411-26.

${ }^{24}$ Radue EW, Kendall BE. Iodide and xenon enhancement of computed tomography $(\mathrm{CT})$ in multiple sclerosis (MS). Neuroradiology 1978;15(3): 153-8.

${ }^{25}$ Haughton VM, Ho KC, Williams AL, Eldevik O. CT detection of demyelinated plaques in multiple sclerosis. AJR 1979;132(2):213-5.

${ }^{26}$ Neetens, A, Hendrata Y, Van Rompaey J. Pattern and flash visual evoked responses in multiple sclerosis. $J$ Neurol 1979;220:113-24.

${ }^{27}$ Asselman P, Chadwick DW, Marsden CD. Visual evoked responses in the diagnosis and management of patients suspected of multiple sclerosis. Brain 1975;98:261-82.

${ }^{28}$ Oepen, G, Brauner CHR, Doerr M, Thoden U. Visual evoked potentials (VEP) elicited by checkerboard versus foveal stimulation in multiple sclerosis. A clinical study in 235 patients. Arch Psychiat Nervenkr 1981;229:305-13.

${ }^{29}$ Jewett DL, Williston JS. Auditory evoked far fields averaged from the scalp of humans. Brain 1971;94:681-96.

${ }^{30}$ Ongerboer de Visser BW, Goor C. Electromyographic and reflex study in idiopathic and symptomatic trigeminal neuralgias: latency of the jaw and blink reflex. $J$ Neurol Neurosurg Psychiatry 1974;37(11):1225-30.

${ }^{31}$ Kimura J. Electrically elicited blink reflex in diagnosis of multiple sclerosis. Review of 260 patients over a seven-year-period. Brain 98(3):413-26.

${ }^{32}$ Mancini G, Carbonara AO, Heremans JF. Immunochemical Quantification of Antigens by Single Radial Immunodiffusion. Immunochemistry 1965;2:235-44.

${ }^{33}$ Delmotte P. Gel isoelectric focussing of cerebrospinal fluid proteins: a potential diagnostic tool. J Clin Chem Biochem 1971;9:334.

${ }^{34}$ Hyllenstedt K, Moller DM. Follow-up on patients with a history of optic neuritis. Acta Ophthalmol 1961;39:655-62.

${ }^{35}$ Matthews WB, Small DG, Small M, Putney E. Pattern reversal evoked visual potential in the diagnosis of multiple sclerosis. J Neurol Neurosurg Psychiatry 1977;40:1009-14.

${ }^{36}$ Feasby TE, Ebers GC. Risk of multiple sclerosis in isolated optic neuritis. J Can Sci Neurol 1982:9(2):269.

${ }^{37}$ Sandberg-Wollheim M, Bynke H. Cerebrospinal fluid in 
25 cases of optic neuritis. Acta Neurol Scand 1973;49:443-53.

${ }^{38}$ Hutchinson WM. Acute optic neuritis and the prognosis for multiple sclerosis. J Neurol Neurosurg Psychiatry 1976;39:283-9. 